\title{
Ação de dentifrício com peróxido de hidrogênio sobre resina composta nanoparticulada
}

\author{
Action dentifrices whit hydrogen peroxide in composite resin nanoparticulate
}

\author{
Rafaela Silva Oliveira ${ }^{1}$, Max José Pimenta Lima² Elisângela de Jesus Campos ${ }^{3^{*}}$ \\ ${ }^{1}$ Mestranda do Programa de Pós-graduação Processos Interativos dos Órgãos e Sistemas (ICS/UFBA); ${ }^{2}$ Professor \\ Adjunto de Bioquímica do Instituto de Ciências da Saúde (ICS/UFBA); ${ }^{3}$ Professora Adjunta de Bioquímica Oral do \\ Instituto de Ciências da Saúde (ICS/UFBA)
}

\begin{abstract}
Resumo
Introdução: O peróxido de hidrogênio é o agente químico mais utilizado no clareamento dental. Além do uso em consultório, também está associado a agentes branqueadores presentes nos dentifrícios. Objetivo: Avaliar in vitro a ação de diferentes dentifrícios branqueadores sobre a cor, rugosidade e massa de uma resina composta nanoparticulada após escovação simulada por 6, 12 e 24 meses. Metodologia: Foram confeccionados 40 corpos de prova da resina composta nanoparticulada FILTEK Z350 XT, divididos em 04 grupos ( $n=10)$ : grupo de controle (GC-água deionizada) e grupos de teste (GT1-Colgate Total 12, GT2- Colgate Luminous White Instant e GT3- Colgate Luminous White Advanced). Os corpos de prova foram escurecidos com café solúvel e submetidos a escovação simulada por 6,12 e 24 meses. Avaliações de cor, rugosidade e massa foram realizadas após cada período de escovação. Resultados: Houve diferença significativa na alteração de cor nos grupos de teste, contudo o GT2 apresentou diferença estatística quando comparado com o GT1 e GT3. Os dentifrícios não promoveram alterações significativas na rugosidade e na massa dos corpos de prova de resina nanoparticulada, após os períodos de escovação simulada nos grupos de teste. Conclusão: A escovação simulada com dentifrícios de uso convencional e branqueadores foi eficaz na remoção da pigmentação extrínseca em resina composta nanoparticulada, tornando-a mais clara, sem causar danos à sua estrutura. Contudo, a presença do agente químico clareador peróxido de hidrogênio não melhorou a percepção visual da cor da resina quando comparado ao dentifrício branqueador que continha a associação de agentes branqueadores mecânicos e óptico.
\end{abstract}

Palavras-chave: Peróxido de Hidrogênio. Dentifrícios. Branqueamento Dentário.

\begin{abstract}
Introduction: Hydrogen peroxide is the most commonly used chemical agent in tooth whitening. In addition to office use, it is also associated with whitening agents present in toothpastes. Objective: To evaluate in vitro the action of different whitening dentifrices on the color, roughness and mass of nanoparticulate composite resin after simulated brushing for 6,12 and 24 months. Methodology: Forty specimens of FILTEK Z350 XT nanoparticulate composite resin were made, divided into 04 groups $(n=10)$ : control group (GC-deionized water) and test groups (GT1-Colgate Total 12, GT2-Colgate Luminous White Instant and GT3-Colgate Luminous White Advanced). The specimens were darkened with instant coffee and submitted to simulate brushing for 6, 12 and 24 months. Color, roughness and mass evaluations were performed after each brushing period. Results: There was a significant difference in color change in the test groups and GT2 showed statistical difference compared to GT1 and GT3. The dentifrices did not promote significant changes in the roughness and mass of the nanoparticulate resin specimens after the simulated brushing periods in the test groups. Conclusion: Simulated brushing with conventional toothpastes and bleaches was effective in removing extrinsic pigmentation in nanoparticulate composite resin, making it clearer without causing damage to its structure. However, the presence of the hydrogen peroxide bleaching agent did not improve the visual perception of resin color when compared to the bleaching dentifrice that contained the combination of mechanical and optical bleaching agents.
\end{abstract}

Keywords: Hydrogen Peroxide. Dentifrices. Teeth Whitening.

\section{INTRODUÇÃO}

A busca constante pela estética e pelos modelos de beleza estabelecidos pela mídia fez a procura da população por dentifrícios branqueadores se tornar mais frequente. As principais funções terapêuticas dos denti-

Correspondente/Corresponding: *Elisângela de Jesus Campos - Instituto de Ciências da Saúde (UFBA), Programa de Pós-Graduação em Processos Interativos dos Órgãos e Sistemas -End: Av. Reitor Miguel Calmon, s. n. Vale do Canela. Salvador (BA). Cep: 40.110-902 -Tel: (71) 3283-8891 _E- mail: elis.campos@terra.com.br frícios estão relacionadas à redução de cáries, remoção do biofilme bacteriano, prevenção da deposição de cálculo e redução da sensibilidade dentinária. No contexto estético, a função primordial de um dentifrício é prevenir ou remover manchas, possibilitando o branqueamento dentário (SILVA et al., 2014).

A cor dos dentes decorre das propriedades de dispersão e absorção da luz pelo esmalte e pela dentina e está associada à adsorção de cromógenos sobre a superfície do esmalte e da película adquirida. $O$ escurecimento 
dentário é uma das queixas mais comuns relatadas pelos pacientes e, em função disso, muitas opções para o branqueamento dentário têm sido disponibilizadas, tanto para o uso em consultório como caseiro (JOINER; LUO, 2017; LIPPERT, 2013).

A determinação da cor do dente ocorre a partir do espaço tridimensional de cores CIELAB. O sistema CIELAB é configurado por três parâmetros: Luminosidade ( $\left.L^{*}\right)$, que varia entre 0 a 100; cores nos tons vermelho-verde $\left(a^{*}\right)$ e amarelo-azul ( $\left.b^{*}\right)$, que variam de $-80 a+80$. Valores positivos de $a^{*}$ indicam tons avermelhados, e os negativos indicam tons verdes; valores positivos de $b^{*}$ indicam tons amarelados, e os negativos indicam tons azuis. Já valores próximos ao zero indicam tons mais neutros, como branco e cinza. Assim, quanto maior o valor de L* e menor os valores de $a^{*}$ e $b^{*}$, mais claro e branco será o dente (TAO et al., 2017; WESTLAND et al., 2017). Portanto, esse sistema é considerado um modelo clássico para determinar, quantitativamente, a variação de cor $(\Delta \mathrm{E})$. Quanto maior o valor $\Delta \mathrm{E}$, maior será a percepção da diferença de cor pelo olho humano (JOINER; LUO, 2017).

A técnica de clareamento dentário está baseada no uso de agentes oxidantes, como o peróxido de hidrogênio, com intuito de romper as ligações das partículas orgânicas dos pigmentos. Já o branqueamento dentário pode ser obtido pela remoção mecânica das manchas na superfície do esmalte mediante o uso de agentes abrasivos, como a sílica ou pela ação do agente óptico blue covarine, um pigmento azul que promove mudanças ópticas nas superfícies dos dentes pelo recobrimento da superfície do esmalte (AWDAH et al., 2017; ODILON et al., 2018).

Nas formulações dos dentifrícios branqueadores podem ser encontrados agentes de branqueamento mecânicos (abrasivos), químicos (peróxidos) e ópticos (blue covarine), associados ou não, dependendo de seu modo de ação (JOINNER; LUO, 2017; LIPPERT, 2013).

$O$ peróxido de hidrogênio $\left(\mathrm{H}_{2} \mathrm{O}_{2}\right)$ é o agente químico mais utilizado no clareamento dental, podendo ser encontrado sob a forma de peróxido de hidrogênio ou derivado do peróxido de carbamida, uma vez que esse último reage com água liberando moléculas de $\mathrm{H}_{2} \mathrm{O}_{2}$. Trata-se de uma molécula instável que, ao entrar em contato com a estrutura dentária, sofre uma sequência de reações resultantes da sua dissociação. Os compostos formados não promovem danos aos tecidos duros do dente, bem como às restaurações de resinas compostas (HARDMAN; MOORE; PETTEWAY 1985; TORRES et al., 2014). Utilizado também em processos de branqueamento nas indústrias têxtil, de papel e celulose, além da área médica, a presença do peróxido de hidrogênio deve ser monitorada, evitando-se danos celulares (CIOLINO; LEVINE, 1997).

Durante o processo de dissociação do $\mathrm{H}_{2} \mathrm{O}_{2}$, ocorre a liberação de radicais livres com elétrons desempareIhados que reagem com as moléculas dos cromógenos, rompendo suas ligações tornando as cadeias menores, numa reação de óxido-redução, que gera o efeito óptico de clareamento, e reduz a absorção da luz dessas estru- turas. Algumas condições podem influenciar a reação, entre elas a concentração do peróxido, a temperatura, a presença de sais de metais, a luz incidente e o pH (ROSELINO et al., 2015).

Nesse contexto, visando a atender às demandas estéticas dos pacientes, foram lançados no mercado produtos branqueadores de venda livre, que prometem eficácia em um curto prazo, como ocorre com os dentifrícios e enxaguatórios, não sendo necessários a prescrição e o acompanhamento profissional, s. Esses produtos possuem, em sua formulação, baixas concentrações de peróxido de hidrogênio, com variação de 1 a $2 \%$ (DAHL; PALLESEN, 2003).

Os dentifrícios, além de auxiliarem na remoção do biofilme e na eliminação das manchas superficiais, em função da incorporação de abrasivos, algumas formulações foram acrescidas com o peróxido de hidrogênio, para agirem sobre cromógenos na superfície dental (TORRES et al., 2014). Os cromógenos se depositam sobre os dentes, $\mathrm{e}$ pela ação química do peróxido de hidrogênio suas cadeias são rompidas, havendo, assim, um aumento da percepção de branqueamento. A eficácia do efeito branqueador dos dentifrícios, contudo, é inferior, quando comparada ao clareamento profissional (CAREY, 2014).

As resinas compostas são utilizadas nos procedimentos restauradores com o propósito de preservar a estética do sorriso. A lisura superficial das restaurações feitas com resina composta representa um dos critérios imprescindíveis para o sucesso ou insucesso do tratamento, visto que a rugosidade da superfície pode implicar alterações clínicas, como manchas, retenção de alimentos, acúmulo de biofilme, cáries secundárias e danos à saúde periodontal (AWDAH et al., 2017).

Apesar das evidências científicas, não há consenso na literatura sobre o efeito do uso dos dentifrícios branqueadores com peróxido de hidrogênio sobre os tecidos dentários duros e os materiais restauradores estéticos. As diferentes metodologias usadas, muitas vezes, impossibilitam a comparação entre os estudos, bem como o tipo de material restaurador estético avaliado. Desse modo, este estudo se propõe avaliar a ação de um dentifrício branqueador que contém peróxido de hidrogênio sobre uma resina composta nanoparticulada, referida como material de eleição na prática clínica odontológica.

O objetivo deste estudo foi avaliar, in vitro, a ação de diferentes dentifrícios branqueadores sobre a rugosidade, a massa e a cor de uma resina composta nanoparticulada, após escovação simulada por 6, 12 e 24 meses.

\section{METODOLOGIA}

Para a realização deste estudo experimental, in vitro, foram preparados 40 corpos de prova de resina composta nanoparticulada FILTEK Z350 XT (3MESPE ${ }^{\circledR}$, Dental Products, St. Paul, Minessota, EUA), cor A2B, divididos aleatoriamente em 4 grupos (Quadro 1). Foram avaliados os parâmetros cor, rugosidade e massa, após teste de 
abrasão realizado em máquina de escovação simulada, com diferentes dentifrícios.

A seleção do compósito, após a revisão da literatura, ocorreu em função da menor rugosidade superficial apre- sentada por esse material. Um único operador realizou todas as leituras referentes a cor, rugosidade e massa, antes e depois dos períodos de 6, 12 e 24 meses de escovação simulada.

\section{Grupos experimentais}

Quadro 1 - Divisão dos grupos de acordo com composição, fabricante e dentifrícios selecionados.

\begin{tabular}{|c|c|c|c|c|c|}
\hline & \multirow[b]{2}{*}{ Dentifrícios/solução } & \multirow[b]{2}{*}{ Composição/fabricante } & \multicolumn{3}{|c|}{ Agentes branqueadores } \\
\hline & & & Agente mecânico & $\begin{array}{l}\text { Agente } \\
\text { químico }\end{array}$ & Agente óptico \\
\hline 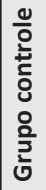 & GC-Água deionizada & - & - & - & - \\
\hline \multirow{3}{*}{ 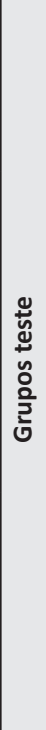 } & $\begin{array}{l}\text { GT1-Colgate Total } 12 \\
\text { Clean Mint }\end{array}$ & $\begin{array}{l}\text { Fluoreto de sódio } 0,32 \% \text { ( } 1450 \mathrm{ppm} \text { flúor), triclosan } 0,3 \% \text {, } \\
\text { água, sorbitol, sílica hidratada, lauril sulfato de sódio, PVM/ } \\
\mathrm{MA}^{\bullet} \text { copolímero, aroma, carragenina, hidróxido de sódio, } \\
\text { sacarina sódica, Cl } 77891^{*} \text {, limoneno. } \\
\text { Colgate-Palmolive. }\end{array}$ & Sílica hidratada. & - & - \\
\hline & $\begin{array}{l}\text { GT2-Colgate Luminous } \\
\text { White Instant White }\end{array}$ & $\begin{array}{l}\text { Fluoreto de sódio } 0,243 \% \text { (1100ppm flúor). água, sílica hi- } \\
\text { dratada, sorbitol, glicerina, PEG-12", trifosfato de pentasódio, } \\
\text { pirofosfato de tetrapotassio, lauril sulfato de sódio, aroma, } \\
\text { goma de celulose, cocamidopropil de betaína, sacarina só- } \\
\text { dica, goma de xantana, hidróxido de sódio, hidroxipropil me- } \\
\text { tilcelulose, propilenoglicol, polisorbato } 80, \text { mica, } \mathrm{Cl} 77891^{*} \text {, } \\
\mathrm{Cl} 73360^{* *} / \text { rojo } 30, \mathrm{Cl} 17200^{* *} / \text { rojo ácido } 33, \mathrm{Cl} 42051^{* * *} / \\
\text { azul ácido } 3 \text {, eugenol. } \\
\text { Colgate-Palmolive. }\end{array}$ & $\begin{array}{l}\text { Sílica hidratada, pi- } \\
\text { rofosfato de tetra- } \\
\text { potássio, mica. }\end{array}$ & - & $\begin{array}{c}\mathrm{Cl} 74160 \\
\text { (blue covarine). }\end{array}$ \\
\hline & $\begin{array}{l}\text { GT3-Colgate Luminous } \\
\text { White Advanced Expert }\end{array}$ & $\begin{array}{l}\text { Peróxido de hidrogênio 2\%, monofluorfosfato de sódio 0,76\% } \\
\text { (1000 ppm de flúor). Propileno glicol, pirofosfato de cálcio, } \\
\text { PVP-peróxido de hidrogênio, PEG/PPG-116/copolímero 66", } \\
\text { PEG-12", glicerina, aroma, lauril sulfato de sódio, sílica, PVP, } \\
\text { pirofosfato tetrasódico, sacarina sódica, pirofosfato dissódi- } \\
\text { co, sucralose, BHT, eugenol. } \\
\text { Colgate-Palmolive. }\end{array}$ & $\begin{array}{l}\text { Sílica, pirofosfato } \\
\text { de cálcio. }\end{array}$ & $\begin{array}{l}\text { Peróxido de } \\
\text { hidrogênio } \\
2 \%\end{array}$ & - \\
\hline
\end{tabular}

•Polivinilmetil-éter, "dióxido de titânio, "polidimetilsiloxano, " ${ }^{* *}$ pigmento vermelho, ${ }^{* * *}$ pigmento azul patente.

Fonte: Autoria própria

\section{Obtenção dos corpos de prova}

Para a confecção dos corpos de prova, foi utilizada uma matriz metálica bipartida de $5 \mathrm{~mm}$ de diâmetro e $3 \mathrm{~mm}$ de espessura (Odeme ${ }^{\circledR}$ ), através de incrementos sucessivos de resina FILTEK Z350 XT, sendo, no último, posicionada uma tira de poliéster e uma lâmina de vidro na porção superior, com o objetivo de padronizar as superfícies de leitura. Nessa mesma área, foi realizada pressão digital sobre uma lâmina de vidro, com o intuito de extravasar o excesso de material e deixar a superfície com maior lisura superficial (ALVES et al., 2014). A fotopolimerização foi realizada com Fotopolimerizador Dabi Atlante DB (Dabi ${ }^{\circledR}$, intensidade > $500 \mathrm{~m} \mathrm{~W} / \mathrm{cm}^{2}$, Ribeirão Preto, Brasil), de acordo com instruções do fabricante $\left(3 \mathrm{M}^{\circledR}\right.$, Minessota, EUA).

\section{Estabilização da massa}

Inicialmente, os corpos de prova foram mantidos em água deionizada a 37으 e em estufa microbiológica Q316M
(Quimis ${ }^{\circledR}$ Ltda., São Paulo, Diadema, Brasil), simulando o ambiente bucal em recipientes individuais, devidamente identificados, até a completa estabilização da massa (g), verificada por pesagem diária e entre as leituras para se avaliar a perda de peso após cada etapa de escovação.

\section{Incorporação em resina ortoftálica}

Após estabilização da massa, os corpos de prova de resina composta nanoparticulada foram fixados em Resina Cristal Ortoftálica ${ }^{\circledR}$, de modo que somente a superfície a ser analisada ficasse exposta.

\section{Polimento dos corpos de prova}

Cada corpo de prova foi polido em politriz metalográfica (PL V060/Biopdi, São Carlos, SP, Brasil) com lixas d'água, em granulação crescente $(400,600$ e 1200) e em baixa velocidade (OLIVEIRA, 2011). 


\section{Escurecimento dos corpos de prova}

Após o polimento, todos os corpos de prova foram mantidos em solução de café solúvel a $37^{\circ}$ durante 14 dias, com trocas diárias, para o escurecimento (ANFE, 2009).

\section{Escovação simulada}

Para a execução do teste de abrasão, foram realizados, ao todo, 100.000 ciclos de escovação simulada, correspondendo a dois anos de escovação. Foram analisados 3 intervalos de tempo: 6 meses ( 25.000 ciclos), 12 meses ( 50.000 ciclos) e 24 meses ( 100.000 ciclos). Cada corpo de prova possuía uma escova de cerdas macias (Clean Classic Colgate-Palmolive Company ${ }^{\circledR}$ ), trocada a cada 50.000 ciclos, e uma seringa de $20 \mathrm{ml}$ que injetava $0,4 \mathrm{ml}$ da solução a cada 2 minutos. Para o preparo da solução de pasta, cada dentifrício foi pesado em balança de precisão (modelo AY 220/Shimadzu ${ }^{\circledR}$ do Brasil Ltda., São Paulo, SP, Brasil) e diluído na proporção de 1:2 em água destilada, medindo-se seu pH (TAO et al., 2017).

\section{Limpeza dos corpos de prova}

Para eliminação de qualquer resíduo de dentifrício, os corpos de prova foram lavados em cuba ultrassônica (L-200/Schuster ${ }^{\circledR}$ Ltda, Santa Maria, RS, Brasil) por 10 minutos com água deionizada e secos em papel absorvente, entre cada período de tempo avaliado.

\section{Avaliação de cor}

A mensuração da cor foi realizada através do Espectrofotômetro Easyshade - Vita ${ }^{\circledR}$ (VITA ${ }^{\circledR}$, Bad Sãckingen Geermany), o qual fornece leituras no sistema CIE L* a* b*. As leituras de cor foram obtidas após o processo de escurecimento e após a escovação simulada nos períodos de 6, 12 e 24 meses.

\section{Avaliação da rugosidade}

A determinação da rugosidade foi realizada através de rugosímetro (Modelo SJ 201 Mitutoyo ${ }^{\circledR}$, Kawasaki, Japão), e as leituras foram feitas em quatro direções distintas em cada corpo de prova, obtendo-se a média das quatro aferições ao final, utilizando o cutt-off de 0,80mm e o " $N$ " (número fragmentação da leitura) em 5 , de forma que a ponta do sensor percorresse toda a dimensão em linha reta do corpo de prova em cada direção.

\section{Avaliação da massa}

A mensuração da massa, em gramas, dos 40 corpos de prova foi obtida em triplicata antes e após os tempos de 6, 12 e 24 meses de escovação, utilizando-se uma balança de precisão modelo AY 220 (Shimadzu ${ }^{\circledR}$ do Brasil Ltda., São Paulo, SP, Brasil).

\section{Análise estatística}

Os dados foram analisados a partir dos critérios de variação de $\operatorname{cor}(\Delta \mathrm{E})$, rugosidade (Ra- $\mu \mathrm{m})$ e massa $(\mathrm{g})$. A análise estatística (mediana, valor mínimo e valor máximo) dos resultados foi realizada no software SPSS $22^{\circledR}$. Com o objetivo de identificar a associação entre os grupos controle e testes, utilizou-se o teste não paramétrico de Kruskal-Wallis, seguido, posteriormente, do teste de Mann-Whitney. O nível de significância adotado para o estudo foi de $5 \%(p \leq 0,05)$.

\section{RESULTADOS}

\section{Avaliação de cor}

Os resultados deste estudo demonstraram que houve alteração de cor identificável através do espectrofotômetro (Vita ${ }^{\circledR} /$ Modelo3D Master, Petrópolis RJ) em todos os grupos, controle e testes, obtendo-se superfícies mais claras, nos tempos estudados. A variação de cor $(\Delta E)$ entre os tempos inicial e 6, 12 e 24 meses de escovação demonstraram que todos os grupos teste obtiveram diferença estatística em comparação com o grupo $\mathrm{GC}(\mathrm{p}=0,00)$. O grupo GT2 apresentou diferença estatística quando comparado com GT1 ( $p=0,00)$, de uso convencional, e GT3 $(p=0,00)$, com peróxido de hidrogênio (Tabela 1$)$.

Tabela 1 - Mediana (valor mínimo - valor máximo) da variação de cor ( $\Delta E$ ) em função do grupo e do tempo.

\begin{tabular}{|c|c|c|c|c|}
\hline Grupo & Dentifrícios & $\Delta \mathrm{E} 6$ meses - inicial & $\Delta \mathrm{E} 12$ meses -inicial & $\Delta \mathrm{E} 24$ meses - inicial \\
\hline GC & Água & $0,90(0,24-1,94) a$ & $1,06(0,79-2,79) a$ & $1,64(0,72-2,50) a$ \\
\hline GT1 & Colgate Total 12 & $5,23(4,09-6,75) b$ & $5,67(4,39-6,99) b$ & $6,07(4,69-7,18) b$ \\
\hline GT2 & Colgate Luminous White Instant & $8,42(7,28-9,52) c$ & $8,92(7,23-10,65) c$ & $9,09(7,81-10,90) c$ \\
\hline \multirow[t]{2}{*}{ GT3 } & Colgate Luminuos White Advanced & $5,78(4,62-7,51) b$ & $6,13(4,91-10,65) b$ & $6,49(5,17-8,10) b$ \\
\hline & & $p=0,00$ & $p=0,00$ & $p=0,00$ \\
\hline
\end{tabular}

Nota - Letras minúsculas distintas na vertical indicam diferenças estatisticamente significativas $(p \leq 0,05)$ entre os grupos.

Fonte: Dados da pesquisa 
Gráfico 1 - Mediana da variação de cor $(\Delta E)$ em função do grupo e do tempo.

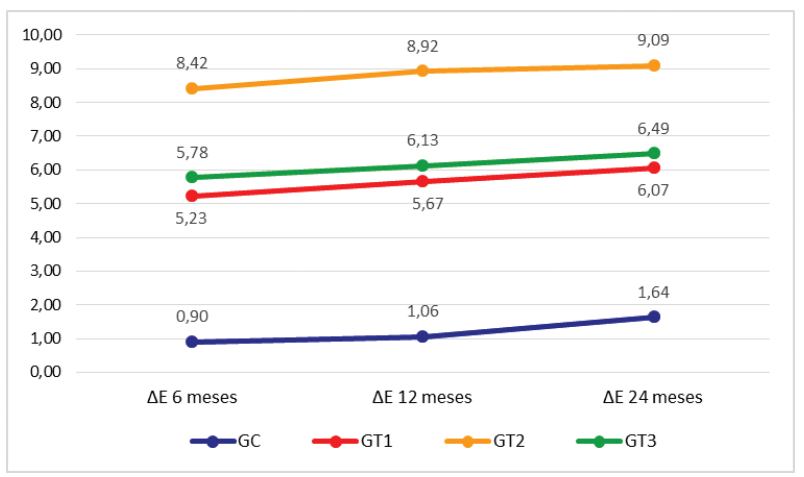

Fonte: Dados da pesquisa

Tabela 2 - Mediana (valor mínimo - valor máximo) da rugosidade (Ra) em função do grupo e do tempo.

\begin{tabular}{|c|c|c|c|c|c|}
\hline Grupo & Dentifrícios & Ra - inicial & $\mathrm{Ra}-6$ meses & $\mathrm{Ra}-12$ meses & $\mathrm{Ra}-24$ meses \\
\hline GC & Água & $0,165(0,11-0,26) a$ & $0,155(0,08-0,18) a$ & $0,170(0,08-0,19) a$ & $0,155(0,08-0,18) a$ \\
\hline GT1 & Colgate Total 12 & $0,160(0,12-0,22) a$ & $0,120(0,08-0,16) a$ & $0,115(0,07-0,17) b c$ & $0,095(0,07-0,15) b c$ \\
\hline GT2 & $\begin{array}{l}\text { Colgate Luminous White } \\
\text { Instant }\end{array}$ & $0,185(0,15-0,23) a$ & $0,140(0,11-0,20) a$ & $0,130(0,09-0,17) b c$ & $0,135(0,09-0,16) a b c$ \\
\hline \multirow[t]{2}{*}{ GT3 } & $\begin{array}{l}\text { Colgate Luminous White } \\
\text { Advanced }\end{array}$ & $0,180(0,15-0,24) a$ & $0,140(0,12-0,21) a$ & $0,140(0,10-0,22) a b c$ & $0,130(0,11-0,16) a b c$ \\
\hline & & $p=0,63$ & $p=0,19$ & $p=0,03$ & $p=0,02$ \\
\hline
\end{tabular}

Nota - Letras minúsculas distintas na vertical indicam diferenças estatisticamente significativas $(p \leq 0,05)$ entre os grupos.

Fonte: Dados da pesquisa

Gráfico 2 - Mediana da rugosidade ( $R a$ ) em função do grupo e do tempo.

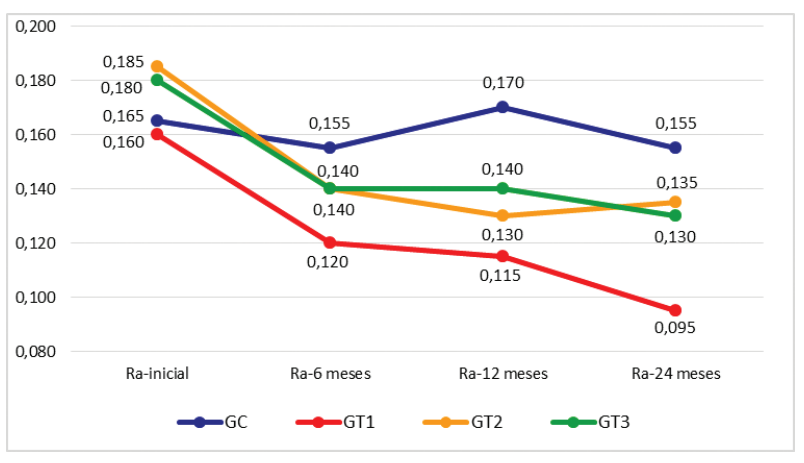

Fonte: Dados da pesquisa

\section{Avaliação da rugosidade}

Em relação à rugosidade superficial, não houve diferença estatística entre os grupos no período inicial $(p=0,63)$, demonstrando que houve padronização das amostras. No tempo de 6 meses, também não houve diferença estatística entre os grupos $(p=0,19)$.

Após 12 meses, verificou-se diferença estatística entre os grupos experimentais $(p=0,03)$; essa diferença se deu entre os grupos GC e GT1 ( $p=0,023)$ e entre os GC e GT2 $(p=0,009)$. Aos 24 meses, também ocorreu diferença estatística entre os grupos $(p=0,02)$, havendo diferença entre os grupos GC e GT1 ( $p=0,009)$. Entretanto todos os grupos apresentaram diminuição da rugosidade superficial após 24 meses de escovação simulada, quando comparados no tempo inicial, evidenciando que houve o polimento das superfícies em todos os grupos (Tabela 2). 
Tabela 3 - Mediana (valor mínimo - valor máximo) e variação da $\Delta$ Ra em função do grupo e do tempo.

\begin{tabular}{llcrr}
\hline Grupo & \multicolumn{1}{c}{ Dentifrícios } & $\Delta$ Ra -6 meses & $\Delta R a-12$ meses & \multicolumn{1}{c}{$\Delta$ Ra -24 meses } \\
\hline GC & Água & $-0,030(-0,08-0,04) \mathrm{a}$ & $-0,015(-0,08-0,05) \mathrm{a}$ & $-0,030(-0,08-0,04) \mathrm{a}$ \\
GT1 & Colgate Total 12 & $-0,050(-0,07-0,02) \mathrm{a}$ & $-0,050(-0,08-0,03) \mathrm{bc}$ & $-0,060(-0,1--0,05) \mathrm{bc}$ \\
\multirow{2}{*}{ GT2 } & $\begin{array}{l}\text { Colgate Luminous White } \\
\text { Instant }\end{array}$ & $-0,040(-0,7--0,01) \mathrm{a}$ & $-0,055(-0,1--0,02) \mathrm{bc}$ & $-0,050(-0,11--0,03) \mathrm{bc}$ \\
GT3 & $\begin{array}{l}\text { Colgate Luminous White } \\
\text { Advanced }\end{array}$ & $-0,025(-0,08-0,02) \mathrm{a}$ & $-0,040(-0,07-0,00) \mathrm{abc}$ & $-0,060(-0,09--0,02) \mathrm{bc}$ \\
\hline & $\mathrm{p}=0,357$ & $\mathrm{p}=0,018$ & $\mathrm{p}=0,011$ \\
\hline
\end{tabular}

Nota - Letras minúsculas distintas na vertical indicam diferenças estatisticamente significativas $(p \leq 0,05)$ entre os grupos.

Fonte: Dados da pesquisa

\section{Avaliação da massa}

A análise da variação da massa demonstrou que não houve diferença estatística significante entre os grupos no tempo inicial e nos períodos de 6, 12 e 24 meses. (Tabela 4)

Tabela 4 - Mediana (valor mínimo - valor máximo) da massa em função do grupo e do tempo.

\begin{tabular}{|c|c|c|c|c|c|}
\hline Grupo & Dentifrícios & Massa inicial & Massa 6 meses & Massa 12 meses & Massa 24 meses \\
\hline GC & Água & $3,856(3,536-4,143)$ & $3,861(3,534-4,124)$ & $3,856(3,5339-4,124)$ & $3,856(3,533-4,123) a$ \\
\hline GT1 & Colgate Total 12 & $3,838(3,689-4,000)$ & $3,837(3,550-3,999)$ & $3,837(3,5483-3,999)$ & $3,836(3,546-3,998) a$ \\
\hline GT2 & $\begin{array}{l}\text { Colgate Luminous } \\
\text { White Instant }\end{array}$ & $3,883(3,689-4,202)$ & $3,881(3,6964,199)$ & $3,877(3,694-4,194)$ & $3,871(3,690-4,191) \mathrm{a}$ \\
\hline \multirow[t]{2}{*}{ GT3 } & $\begin{array}{l}\text { Colgate Luminuos } \\
\text { White Advanced }\end{array}$ & $3,871(3,419-4,217)$ & $3,850(3,4164,205)$ & $3,848(3,415-4,203)$ & $3,845(3,413-4,199) a$ \\
\hline & & $p=0,71$ & $p=0,70$ & $p=0,71$ & $p=0,71$ \\
\hline
\end{tabular}

Nota - Letras minúsculas distintas na vertical indicam falta de significância estatística $(p>0,05)$.

Fonte: Dados da pesquisa

Gráfico 4 - Mediana da massa $(g)$ em função do grupo e do tempo.

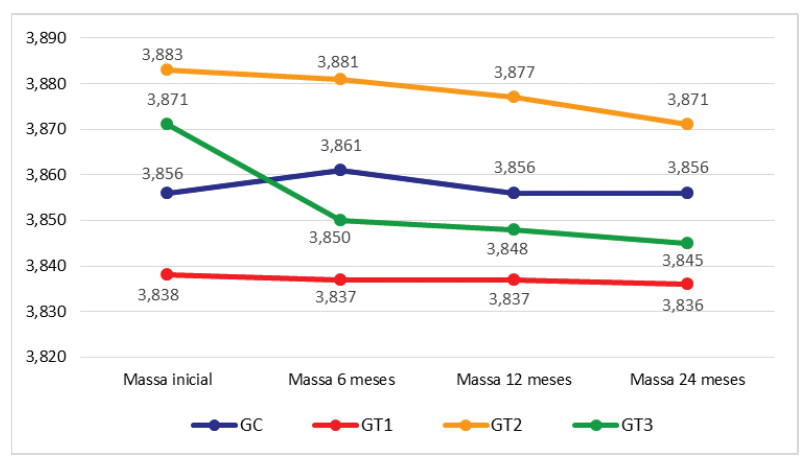

Fonte: Dados da pesquisa

\section{Avaliação do pH}

A avaliação do $\mathrm{pH}$ das soluções dos dentifrícios foi feita em triplicata e mensurada imediatamente após o preparo. Todas as soluções foram preparadas com água destilada (1:2) e apresentaram pH acima do neutro: Colgate Total 12 Clean Mint $(7,19)$, Colgate Luminous White Instant White $(8,57)$ e Colgate Luminous White Advanced Expert $(7,55)$.

\section{DISCUSSÃO}

A escovação simulada por 6, 12 e 24 meses com dentifrícios de uso convencional e branqueadores proporcionou o branqueamento dos corpos de prova de resina composta nanoparticulada e seu polimento superficial, sem promover perda de massa.

O peróxido de hidrogênio é um agente químico instável, sendo utilizado em diferentes concentrações para a obtenção do branqueamento dentário (HARDMAN; MOORE; PETTEWAY 1985; TORRES et al., 2014). No presente estudo, o grupo escovado com o dentifrício que continha peróxido de hidrogênio a $2 \%$ não diferiu do grupo escovado com dentifrício convencional, como também não apresentou ação superior ao dentifrício branqueador que continha a associação dos abrasivos sílica e mica. Esse achado pode ser justificado pela instabilidade e pela baixa concentração do peróxido de hidrogênio na formulação do dentifrício avaliado.

Em contrapartida o grupo escovado com dentifrício branqueador que continha a associação do agente óptico blue covarine e a associação dos agentes abrasivos mecânicos, sílica hidratada e mica, foi o que obteve a maior variação de cor nos períodos de 6, 12 e 24 meses, indicando redução no tom amarelado dos corpos de prova 
manchados artificialmente pelo café. O blue covarine é um pigmento azul que promove mudanças ópticas nas superfícies dos dentes pelo recobrimento de toda a superfície do esmalte após a escovação (AWDAH et al., 2017; ODILON et al., 2018), como foi verificado em estudo in vitro realizado para avaliar o efeito de dentifrícios branqueadores com blue covarine sobre o esmalte dentário bovino (ODILON et al., 2018).

Os dentifrícios de uso convencional e branqueadores contêm, em sua formulação, além dos abrasivos, o dióxido de titânio. Esse agente é caracterizado como um pigmento de cor branca com função opacificante nos dentifrícios, evitando o aspecto translúcido do produto (FRAZER, 2001).

Revisão sistemática realizada para avaliar a eficácia do branqueamento dental promovido por dentifrícios branqueadores, quando comparados com dentifrícios de uso convencional, demonstrou a ação efetiva dos primeiros devido à presença de componentes abrasivos em sua formulação (CASADO et al., 2018). Esse achado é semelhante ao observado no presente estudo, no qual se verificou o branqueamento dos corpos de provas de resina composta nanoparticulada, nos tempos estudados.

Os componentes abrasivos presentes nos dentifrícios branqueadores influenciam sua abrasividade devido ao tamanho, à forma, dureza e concentração das partículas durante a escovação (ANDRADE JÚNIOR et al., 2000). Em todos os grupos teste, os dentifrícios branqueadores e de uso convencional promoveram polimento das superfícies da resina composta nanoparticulada. Esse resultado foi influenciado pela presença das partículas abrasivas, como a sílica hidratada, em todos os dentifrícios, e a mica, presente no grupo escovado com o dentifrício que continha blue covarine. Além das características físico-químicas dos abrasivos, o baixo pH das soluções dos dentifrícios pode influenciar sua abrasividade. Neste estudo, nenhum dos dentifrícios, ao ser diluído, apresentou $\mathrm{pH}$ abaixo do crítico para desmineralização do esmalte dentário.

Avaliando as superfícies de esmalte e dentina, em dentes bovinos e humanos, e os possíveis danos causados por dentifrícios branqueadores com sílica e blue covarine, após escovação simulada, um estudo in vitro evidenciou que as perdas estruturais foram insignificantes. Concluiu-se que os dentifrícios contendo blue covarine não promoveram alterações negativas sobre a rugosidade dos espécimes em comparação com dentifrícios de uso convencional e os branqueadores à base de sílica (JOINER et al., 2008). Esse resultado corrobora os achados do presente estudo.

Estudo in vitro, realizado com o objetivo de avaliar a rugosidade superficial e a mudança de cor em resinas nanoparticuladas e nano-híbridas, verificou que, depois de 4 anos de escovação simulada com dentifrícios branqueadores, a variação de cor foi diretamente influenciada pelo tempo de escovação e pela abrasividade dos dentifrícios. Contudo, concluiu-se que não houve alteração da rugosidade superficial das resinas compostas testadas em função da abrasividade dos dentifrícios (ROSELINO et al., 2015). Esses resultados estão de acordo com os achados do presente estudo, uma vez que não houve aumento da rugosidade nos grupos teste, quando comparados com o grupo controle, escovado apenas com água destilada.

A ação abrasiva de escovas dentárias foi avaliada em um estudo in vitro, que utilizou escovas de um mesmo fabricante, diferentes marcas e tipos de cerdas (macia, média e dura) sobre o esmalte bovino. Os resultados demonstraram que as escovas de cerdas duras promoveram maior desgaste da superfície, quando comparadas com as de cerdas médias e macias, que apresentaram menor perda de estrutura (FURLAN et al., 2005). Neste estudo, com o objetivo de padronizar o efeito da ação abrasiva exercida pelas escovas durante a escovação simulada, foram utilizadas escovas de cerdas macias devido à sua função menos abrasiva.

Pesquisa in vitro realizada para avaliar a rugosidade superficial de diferentes resinas compostas promovida por dentifrícios de uso convencional, para hipersensibilidade e branqueador, após 2 anos de escovação simulada, demonstrou que quanto maior o tempo de escovação, maior a rugosidade superficial promovida pelo dentifrício branqueador (MONTEIRO; SPOHR, 2015). Esse resultado difere dos achados do presente estudo, no qual os dentifrícios branqueadores não promoveram aumento da rugosidade superficial, promovendo polimento das superfícies. Vale destacar que diferentes metodologias no preparo da solução do dentifrício, bem como no teste de abrasão, foram utilizadas nos estudos, o que justifica tal diferença.

Estudo in vitro desenvolvido para avaliar a influência da escovação simulada na rugosidade superficial em quatro diferentes tipos resinas compostas, através do uso de perfilômetro, após 5.000, 10.000 e 20.000 ciclos de escovação verificou que a resina Filtek Z350 XT apresentou significativamente menor rugosidade comparada às demais resinas avaliadas. Concluindo que a rugosidade das resinas compostas testadas aumentou a cada intervalo de tempo e que não houve diferença na perda de massa entre as amostras estudadas (AL KHURAIF, 2014). Esse achado difere do resultado do presente estudo, no qual não houve aumento da rugosidade superficial dos corpos de prova de resina, havendo o seu polimento. As soluções de pastas utilizadas no referido estudo foram preparadas em uma concentração maior do que a utilizada no presente estudo. Contudo, concordam com relação à perda de massa.

Com base nos resultados encontrados neste estudo, destaca-se a necessidade de padronização, nos testes de abrasão, no que diz respeito ao preparo das soluções de pasta, ao número de ciclos por minuto e à força empregada. As diferentes metodologias utilizadas nos testes de abrasão em resina composta, entre os estudos, dificultam a comparação dos resultados encontrados relativos à rugosidade superficial promovida pelos dentifrícios. 


\section{CONCLUSÃO}

A escovação simulada com dentifrícios de uso convencional e branqueadores foi eficaz na remoção da pigmentação extrínseca em resina composta nanoparticulada, promovida pelo escurecimento com café, tornando-a mais clara, sem causar danos à sua estrutura. Contudo a presença do agente químico clareador peróxido de hidrogênio no dentifrício não melhorou a percepção visual da cor da resina, quando comparado com o dentifrício que continha apenas a associação de agentes branqueadores mecânicos e óptico.

\section{REFERÊNCIAS}

AL KHURAIF, A. A. A. An in vitro evaluation of wear and surface roughness of particulate filler composite resin after tooth brushing. Acta Odontol. Scand., Oslo, v.72, n. 8, p. 977-983, 2014.

ALVES, J. K. G. et al. Avaliação da cor de um compósito com espectrofotômetro em diferentes modos de leitura e condições de armazenagem. RFO, Passo Fundo, v.19, n.1, p. 101-106, jan./abr. 2014.

ANDRADE JÚNIOR, A. C. C. et al. Caracterização físico química dos componentes inorgânicos dos dentifrícios. ABOPREV, São Paulo, v. 2, n. 6, p.50-56, jul. 2000.

ANFE, T. E. A. Avaliação da possibilidade de remoção do manchamento de resinas compostas submetidas ao envelhecimento artificial através do re-polimento. 2009. 93f. Dissertação (Programa de Pós-graduação em Odontologia) - Faculdade de Odontologia da Universidade de São Paulo, 2009.

AWDAH, A. A. et al. The effect of bleaching toothpastes containing blue covarine on enamel color. EC Dental Science, [s.I], v.15, n. 4, p.127-133, 2017.

CAREY, C. M. Tooth whitening: what we now know. J. Evid. Based Dent. Pract., St. Louis, supl., p.70-76, June 2014.

CASADO, B. G. S. et al. Efficacy of dental bleaching with whitening dentifrices: a systematic review. Int. J. Dent., Cairo, v. 2018, p. 8, Oct. 2018.

CIOLINO, H. P.; LEVINE, R. L. Modification of proteins in endothelial cell death during oxidative stress. Free Radic. Biol. Med., New York, v. 22, n. 7, p. 1277-1282, Sept. 1997.

DAHL, J. E.; PALLESEN, U. Tooth bleaching--a critical review of the biological aspects. Crit. Rev. Oral Biol. Med., Boca Raton, v. 14, n. 4, p. 292-304, July 2003.
FRAZER, L. Titanium dioxide: environmental white knight? Environ. Health Perspect., Research Triangle Park, v.109, n. 4, p. A174-A177, Abr. 2001.

FURLAN, G. H.V. et al. Desgaste dental causado por diferentes cerdas de escovas dentais. Rev. Inst. Ciênc. Saúde, São Paulo, v. 23, n. 4, p.305308, out./dez. 2005.

HARDMAN, P. K.; MOORE, D.L.; PETTEWAY, G.H. Stability of hydrogen peroxide as a bleaching agent. Gen. Dent., Chicago, v.33, n.2, p.121122, Mar./Apr. 1985.

JOINER, A. et al. A novel optical approach to achieving tooth whitening. J. Dent., [s.I], n. 36s, p. 8-14, 2008. Available from: http://linkinghub. elsevier.com/retrieve/pii/S0300571208000420. Access in: 11 ago. 2019.

JOINER, A.; LUO, W. Tooth colour and whiteness: a review. J. Dent., [s.I], n. 67, p.3-10, June 2017.

LIPPERT, F. An Introduction to toothpaste - Its purpose, history and ingredients. Monogr. Oral Sci., Basel, v. 23, p.1-14, 2013. DOI: 10.1159/000350456.

MONTEIRO, B.; SPOHR, A. M. Surface roughness of composite resins after simulated toothbrushining with different dentifrices. J. Int. Oral Health, India, v.7, n.7, p.1-5, Apr. 2015.

ODILON, N.N. et al. Avaliação in vitro do efeito de dentifrícios branqueadores contendo blue Covarine sobre o esmalte dentário bovino. Rev. Odontol. UNESP, São Paulo, v. 47, n. 6, p.388-394, nov./dez. 2018.

OLIVEIRA, G.U. Avaliação do desgaste e da alteração da rugosidade superficial em resina compostas de diferentes características submetidas à escovação simulada e ciclagem de pH. 2011. 141f. Dissertação (Mestrado) - Universidade de São Paulo, Bauru, 2011.

ROSELINO, L. M. R. R. et al. Effect of brushing time and dentifrice abrasiveness on color change and surface roughness of resin composites. Braz. Dent. J., Ribeirão Preto, v. 26, n. 5, p. 507-513, 2015.

SILVA, E. M. et al. Effect of toothbrushing-mouthrinse-cycling on surface roughness and topography of nanofilled, microfilled, and microhybrid resin composites. Oper. Dent., Seattle, v. 39, n.5, p.521-529, 2014.

TAO, D. et al. In vitro and clinical evaluation of optical tooth whitening toothpastes. J. Dent., [s.I], n. 67, p.25-28, Dec. 2017. DOI :10.1016/j. jdent.2017.08.014.

TORRES, C. R. G. et al. Influence of $\mathrm{pH}$ on the effectiveness of hydrogen peroxide whitening. Oper Dent., Seattle, v.39, n.6, p.261-268, Nov./Dec. 2014. DOI: 10.2341/13-214-L.

WESTLAND, S. et al. Investigation of the perceptual thresholds of tooth whiteness. J. Dent., [s.I], n.67, p.11-14, Dec. 2017. DOI : 10.1016/j. jdent.2017.09.013.

Submetido em: 04/11/2019

Aceito em: 30/11/2019 